\title{
Cystatin C as a Parameter of Glomerular Filtration Rate in Patients with Ovarian Cancer
}

\author{
Lubomir Bodnar $^{\mathrm{a}}$ Gabriel Benedykt Wcislo ${ }^{\mathrm{a}}$ Marta Smoter $^{\mathrm{a}}$ \\ Agnieszka Gasowska-Bodnar ${ }^{b}$ Rafał Stec $^{\text {a }}$ Agnieszka Synowiec $^{a}$ \\ Cezary Szczylik ${ }^{a}$
}

Departments of ancology and ${ }^{b}$ Gynecology and Gynecological Oncology, Military Institute of Medicine, Warsaw, Poland

\section{Key Words}

Cystatin C • Ovarian cancer - Glomerular filtration rate

\begin{abstract}
Aims: To evaluate the potential role of serum cystatin $C$ as a marker of renal function in patients with ovarian cancer. Methods: Treatment of consecutive ovarian cancer patients who were eligible for chemotherapy with paclitaxel $(135 \mathrm{mg} /$ $\left.\mathrm{m}^{2} / 24 \mathrm{~h}\right)$ and cisplatin $\left(75 \mathrm{mg} / \mathrm{m}^{2}\right)$ every 3 weeks in 6 cycles. Glomerular filtration rate (GFR) markers, i.e. serum levels of creatinine and cystatin C, estimated by the Cockcroft-Gault and Modification of Diet in Renal Disease formulas, were recorded before each cycle and 3 weeks after the 6 th course. Results: The median age of 34 patients was 54 years. In the initial stage of treatment, we did not observe any correlation between cystatin C and other GFR markers. We noted a significant association between cystatin $C$ and tumor extent on spiral CT scans (diameter: $>1 \mathrm{~cm}$ ) performed at baseline $(p=$ $0.004)$, and after the 1 st $(p=0.03)$ and 2 nd cycle $(p=0.026)$. We observed a correlation between cystatin $C$ and CA-125 level before chemotherapy $(R=0.4 ; p=0.02)$ and after the 1st cycle $(R=0.43 ; p=0.04)$. Conclusion: The results of our study suggest that cystatin $C$ is not a reliable marker of the GFR in ovarian cancer patients, probably due to its nature as a cysteine protease inhibitor.

Copyright $\odot 2010$ S. Karger AG, Basel
\end{abstract}

\section{Introduction}

The glomerular filtration rate (GFR) is calculated by the use of the urinary or plasma clearance of inulin, an ideal filtration marker, or by alternative exogenous markers such as iothalamate, diethylene triamine pentaacetic acid (Cr-EDTA) and iohexol. Exogenous marker employment in clearance measurement is complex, expensive and difficult to do in routine clinical practice [1]. GFR calculation methods are mostly based on the creatinine serum level. Creatinine is secreted by proximal tubular cells as well as filtered by the glomerulus; thus, the creatinine clearance exceeds the GFR. Tubular secretion of creatinine varies among individuals, especially in those with a mild-to-moderate reduction in GFR [2]. Estimating equations include variables such as age, sex, race and body size, in addition to serum creatinine, as surrogates for muscle mass and, therefore, they can overcome some limitations of the use of serum creatinine alone. An estimating equation is derived by the use of regression techniques to model the observed relation between marker serum level and measured GFR in a study population. Two creatinine-based equations, the Cockcroft-Gault (ClCG) and the Modification of Diet in Renal Disease (MDRD) formulas, have been extensively studied and widely applied [3].

\section{KARGER \\ Fax +41613061234 E-Mail karger@karger.ch} www.karger.com

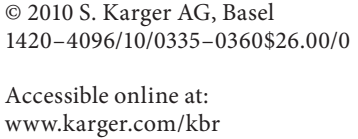

Lubomir Bodnar

Military Institute of Medicine

Szaserów 128

PL-04-141 Warsaw (Poland)

E-Mail lubo@ esculap.pl 
Recent investigations suggest that cystatin $\mathrm{C}$ may be a better filtration marker than creatinine, especially at higher levels of GFR [4]. Cystatin C, a cysteine proteinase inhibitor, is a 120 -amino-acid basic protein (molecular weight: $13 \mathrm{kDa}$ ) produced by nearly all human cells and released into the bloodstream, filtered by the kidney glomerulus and metabolized in the proximal tubule. This protein belongs to the cystatin superfamily of cysteine protease inhibitors. The production rate of cystatin $\mathrm{C}$ is stable and does not change in inflammatory conditions. Cystatin $\mathrm{C}$ is influenced by glucocorticoids and thyroid dysfunction $[5,6]$. In different clinical trials, cystatin $C$ has been supposed to represent an alternative endogenous GFR marker due to the fact that it is not secreted but reabsorbed by tubule epithelial cells, then catabolized and eliminated mainly by glomerular filtration $[7,8]$.

In malignancy, an imbalance between cysteine proteases and their inhibitors, associated with a metastatic tumor cell phenotype, is thought to facilitate tumor cell invasion and metastasis [9]. Numerous studies have provided evidence of substantial increases in $\mathrm{mRNA}$, protein and the activity of tumor cysteine proteases, accompanied only by a moderate increase in, or unchanged concentrations of, intracellular inhibitors [10]. Enhanced extracellular secretion of cysteine proteases is another feature associated with tumor cell phenotype. A few studies reported that cystatin $C$ levels are elevated in malignant tissues and in body fluids of patients with neoplastic diseases including breast cancer and prostate cancer. This phenomenon is associated with more aggressive forms of these tumors [11-13].

To evaluate its validity in ovarian cancer patients with normal kidney function (GFR $>60 \mathrm{ml} / \mathrm{min} / 1.73 \mathrm{~m}^{2}$ estimated by MDRD formula) treated with cisplatin-based chemotherapy, serum concentrations of cystatin $\mathrm{C}$ and serum creatinine were analyzed and compared with respect to GFR estimation during first-line chemotherapy.

\section{Patients and Methods}

\section{Patients}

The clinical trial design has been previously described [14]. In brief, a prospective, randomized, placebo-controlled and doubleblind phase II trial was conducted at the Department of Oncology, Military Institute of Medicine, Warsaw, Poland.

First, 34 consecutive patients with ovarian cancer after primary surgery, without history of renal diseases, without deviations from normal kidney morphology in imaging studies, with normal kidney function (GFR $>60 \mathrm{ml} / \mathrm{min} / 1.73 \mathrm{~m}^{2}$ estimated by MDRD formula) and qualifying for first-line chemotherapy were prospectively included. The study protocol was approved by the local ethics committee, and written informed consent was obtained from all participants.

The patients were assigned to receive 6 courses of first-line chemotherapy consisting of $135 \mathrm{mg}$ intravenous paclitaxel per square meter of body surface area over a 24 -hour period on day 1 followed by $75 \mathrm{mg}$ intravenous cisplatin per square meter on day 2. Standard premedication (dexamethasone $20 \mathrm{mg}$, clemastine $1 \mathrm{mg}$ and ranitidine $150 \mathrm{mg}$ ) was given intravenously to prevent hypersensitivity reactions to paclitaxel. The treatment was administered every 3 weeks in 6 cycles. Hydration (3,000 $\mathrm{ml}$ of $0.9 \%$ $\mathrm{NaCl}$ ) and antiemetic agents (ondansetron $8 \mathrm{mg}$ ) were administered intravenously before cisplatin. The study medication, magnesium sulfate and magnesium subcarbonate, was administered as previously described [14].

\section{Laboratory Methods}

Serum levels of creatinine, and the ClCG and MDRD formulas were recorded before each cycle (before administration of the standard premedication, hydration and antiemetic agents) and 3 weeks after the 6th course.

Serum creatinine was measured by the kinetic Jaffe reaction, rate blanked with color compensation on a COBAS INTEGRA 800 (Roche Diagnostics, Rotkreuz, Switzerland) with a normal range from 0.55 to $1.02 \mathrm{mg} / \mathrm{dl}$ for women [15]. Albumin (ALB) and blood urea nitrogen (BUN) concentrations were assessed by using commercial kits on the COBAS INTEGRA 800 automated analyzer with a normal range of 3.5-5 g/dl and 10-20 mg/dl, respectively.

Cystatin $\mathrm{C}$ was measured before administration of the standard premedication, hydration and antiemetic agents, using an immunologic turbidimetric assay on the COBAS INTEGRA 800 system using Dako reagents (Dako Diagnostics, Zug, Switzerland) with a normal range from 0.63 to $1.33 \mathrm{mg} / \mathrm{l}$.

Creatinine clearance was calculated by the ClCG formula [16]:

$$
\mathrm{GFR}=\frac{140-A(\text { years }) \times W(\mathrm{~kg}) \times \mathrm{R}}{72 \times \mathrm{Cr}(\mathrm{mg} / \mathrm{dl})},
$$

( $\mathrm{R}$ = coefficient of 0.85 for women; $\mathrm{Cr}=$ serum creatinine level; $\mathrm{A}=$ age; $\mathrm{W}=$ actual weight).

GFR was calculated by the MDRD formula [3] as:

$$
\begin{aligned}
\mathrm{GFR}= & 170 \times[\text { serum } \mathrm{Cr} \text { level }(\mathrm{mg} / \mathrm{dl})]^{-0.999} \\
& \times[\text { age }(\text { years })]^{-0.176} \times 0.762 \text { for women } \\
& \times 1.18 \text { for black women } \times \mathrm{BUN}^{-0.170} \times \mathrm{ALB}^{0.318}
\end{aligned}
$$

\section{Statistical Analysis}

Demographic data are presented as medians or means with SD and 95\% CI. Variables were compared by the Mann-Whitney test. Correlations were assessed by the parametric Pearson and nonparametric Spearman correlation tests, where appropriate. $\mathrm{p}<$ 0.05 was considered to indicate statistical significance.

Using a desired correlation coefficient (R) of 0.50 , indicating an important relationship between cystatin $\mathrm{C}$ and other GFR markers with a two-sided $\mathrm{p}$ value of 0.05 and power of 0.85 , we found the required sample size to be 32 patients [17]. Statistical calculations were performed using the Statistica for Windows version 7.0 software. 
Table 1. Patient characteristics $(n=34)$

\begin{tabular}{|c|c|c|}
\hline & Number & Percentage \\
\hline \multicolumn{3}{|l|}{ Age, years } \\
\hline Median & \multicolumn{2}{|l|}{54} \\
\hline Range & \multicolumn{2}{|c|}{$28-68$} \\
\hline \multicolumn{3}{|l|}{ Stage at diagnosis (FIGO) } \\
\hline I & 3 & 8.8 \\
\hline II & 1 & 2.9 \\
\hline III & 26 & 76.5 \\
\hline IV & 4 & 11.8 \\
\hline \multicolumn{3}{|l|}{ Performance status (ECOG) } \\
\hline 0 & 9 & 26.5 \\
\hline 1 & 24 & 70.6 \\
\hline 2 & 1 & 2.9 \\
\hline \multicolumn{3}{|l|}{ Histology } \\
\hline Serous & 25 & 73.5 \\
\hline Endometrial & 7 & 20.6 \\
\hline Clear-cell & 2 & 5.9 \\
\hline \multicolumn{3}{|l|}{ Primary surgery } \\
\hline Primary radical & 4 & 11.8 \\
\hline Optimal debulking & 9 & 26.5 \\
\hline Suboptimal debulking & 21 & 61.7 \\
\hline Measurable disease on CT scan & 16 & 47.1 \\
\hline \multicolumn{3}{|l|}{$\mathrm{BSA}, \mathrm{m}^{2}$} \\
\hline Mean $\pm \mathrm{SD}$ & \multicolumn{2}{|c|}{$1.73 \pm 0.15$} \\
\hline $95 \% \mathrm{CI}$ & \multicolumn{2}{|c|}{$1.68-1.78$} \\
\hline \multicolumn{3}{|l|}{ Creatinine, $\mathrm{mg} / \mathrm{dl}$} \\
\hline Mean $\pm S D$ & \multicolumn{2}{|c|}{$0.66 \pm 0.14$} \\
\hline $95 \% \mathrm{CI}$ & \multicolumn{2}{|c|}{$0.61-0.71$} \\
\hline \multicolumn{3}{|l|}{$\mathrm{ClCG}, \mathrm{ml} / \mathrm{min}$} \\
\hline Mean $\pm S D$ & \multicolumn{2}{|c|}{$106 \pm 29$} \\
\hline $95 \% \mathrm{CI}$ & \multicolumn{2}{|c|}{$96-117$} \\
\hline \multicolumn{3}{|l|}{ MDRD, $\mathrm{ml} / \mathrm{min} / 1.73 \mathrm{~m}^{2}$} \\
\hline Mean $\pm S D$ & \multicolumn{2}{|c|}{$103 \pm 26$} \\
\hline $95 \% \mathrm{CI}$ & \multicolumn{2}{|c|}{$94-112$} \\
\hline \multicolumn{3}{|l|}{$\mathrm{CA}-125, \mathrm{U} / \mathrm{ml}$} \\
\hline Mean $\pm S D$ & \multicolumn{2}{|c|}{$636 \pm 1,151$} \\
\hline $95 \% \mathrm{CI}$ & \multicolumn{2}{|c|}{$221-1,051$} \\
\hline
\end{tabular}

FIGO = International Federation of Gynecology and Obstetrics; ECOG = Eastern Cooperative Oncology Group; BSA = body surface area.

\section{Results}

\section{Patient Characteristics}

Table 1 summarizes the clinical characteristics of the 34 eligible patients whose data form the basis of this report. Their median age was 54 years (range: $28-68$ years). At baseline, the mean (5th-95th percentile) serum concentrations of creatinine and cystatin $\mathrm{C}$ were 0.66 (0.61$0.71) \mathrm{mg} / \mathrm{dl}$ and $0.72(0.65-0.79) \mathrm{mg} / \mathrm{l}$, respectively. The
Table 2. Cystatin $C$ and measurable residual disease shown by spiral CT scan (diameter: $>1 \mathrm{~cm}$ ) at first presentation before chemotherapy

\begin{tabular}{lllrl}
\hline & \multicolumn{2}{l}{ Median, mg/l } & \multirow{2}{*}{$\mathrm{U}$} & $\mathrm{p}$ \\
\cline { 2 - 3 } & measurable & non-measurable & & \\
\hline Cystatin C (before) & 0.73 & 0.60 & 71.0 & $0.0040^{*}$ \\
Cystatin C (1st) & 0.72 & 0.65 & 99.5 & $0.0298^{*}$ \\
Cystatin C (2nd) & 0.72 & 0.64 & 91.5 & $0.0257^{*}$ \\
Cystatin C (3rd) & 0.69 & 0.67 & 119.0 & 0.2618 \\
Cystatin C (4th) & 0.75 & 0.70 & 100.0 & 0.1253 \\
Cystatin C (5th) & 0.73 & 0.71 & 94.5 & 0.2127 \\
Cystatin C (6th) & 0.78 & 0.74 & 127.0 & 0.3908 \\
\hline
\end{tabular}

$\mathrm{U}=$ Mann-Whitney coefficient. * Significant differences between groups at $\mathrm{p}<0.05$.

mean GFR (5th-95th percentile) calculated by the ClCG and MDRD formulas were $106(96-117) \mathrm{ml} / \mathrm{min}$ and 103 (94-112) $\mathrm{ml} / \mathrm{min} / 1.73 \mathrm{~m}^{2}$, respectively. The majority of the patients with ovarian cancer was at advanced stadium FIGO III or IV.

\section{Correlation among Measures of Renal Function}

Figure 1 shows that there was no relationship ( $\mathrm{p}<$ 0.05) between cystatin $C$ serum concentration and the other GFR markers - serum levels of creatinine and the ClCG and MDRD formulas - before chemotherapy.

After the third cycle of chemotherapy, we observed that cystatin C and GFR assessed by the MDRD formula weakly correlated (Spearman's $\mathrm{R}=-0.36 ; \mathrm{p}=0.03$ ). We did not see any correlation between cystatin $\mathrm{C}$ and serum creatinine or ClCG (fig. 2).

We observed a significant positive relationship between serum cystatin $C$ and creatinine serum concentrations (Spearman's $\mathrm{R}=0.66 ; \mathrm{p}<0.0001$ ), after the 6th cycle of chemotherapy. We noted a correlation between cystatin $\mathrm{C}$ and serum levels of creatinine and MDRD after the 6th cycle of chemotherapy (fig. 3).

\section{Serum Levels of Cystatin C and Ovarian Cancer}

As presented in table 2, we found significant differences in cystatin $\mathrm{C}$ serum level before chemotherapy $(\mathrm{U}=71 ; \mathrm{p}=0.004)$, and after the first $(\mathrm{U}=99.5 ; \mathrm{p}=0.03)$ and second cycles $(\mathrm{U}=91.5 ; \mathrm{p}=0.026)$ depending on the measurable residual disease shown on spiral CT scans (diameter: $>1 \mathrm{~cm}$ ). After the third or later cycles of chemotherapy, we did not observe any significant differenc- 


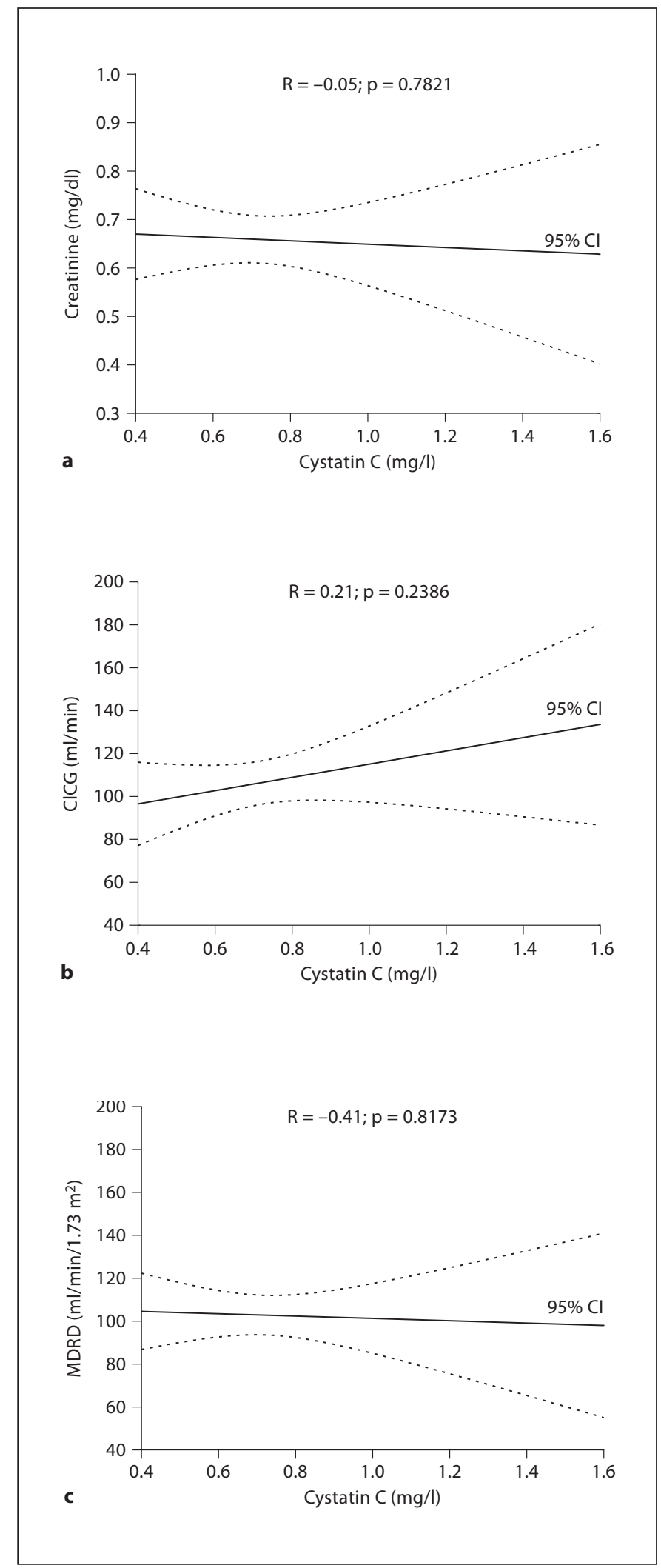

Fig. 1. Correlation between serum cystatin level and creatinine (a), ClCG (b) and MDRD (c) before chemotherapy.
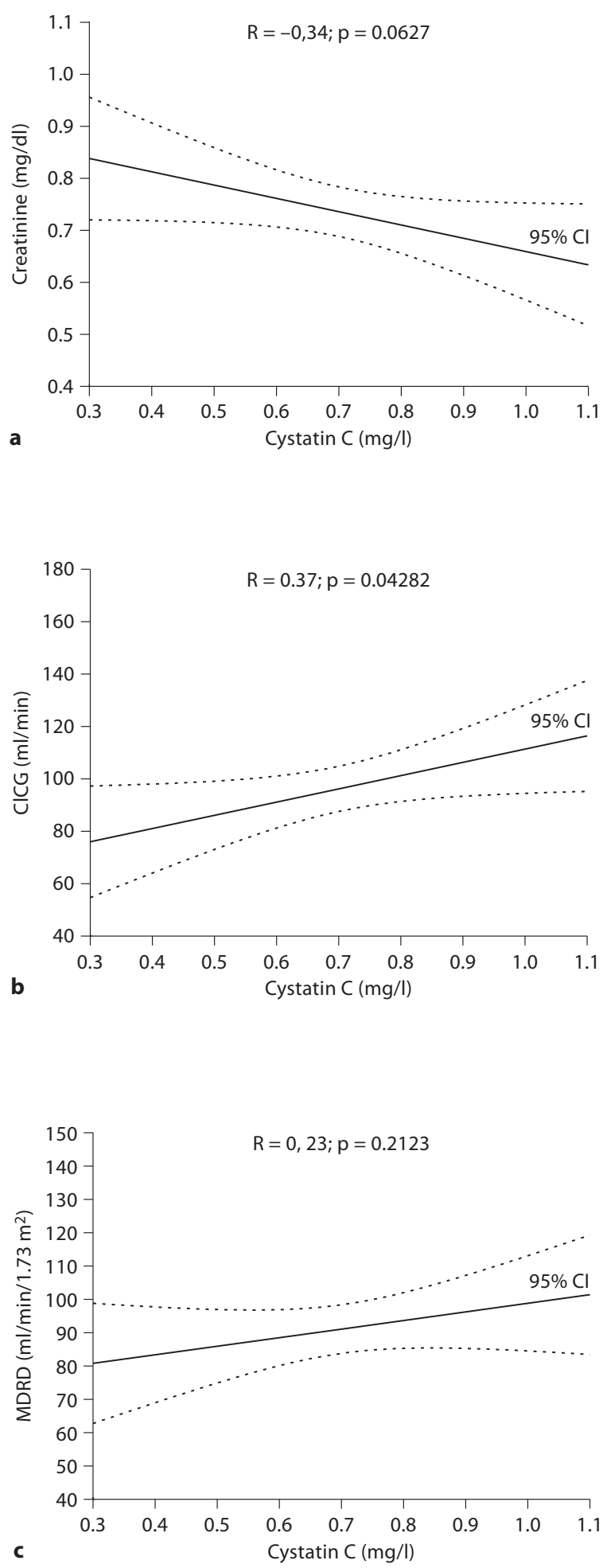

Fig. 2. Correlation between serum cystatin level and creatinine (a), ClCG (b) and MDRD (c) after the third cycle of chemotherapy. 


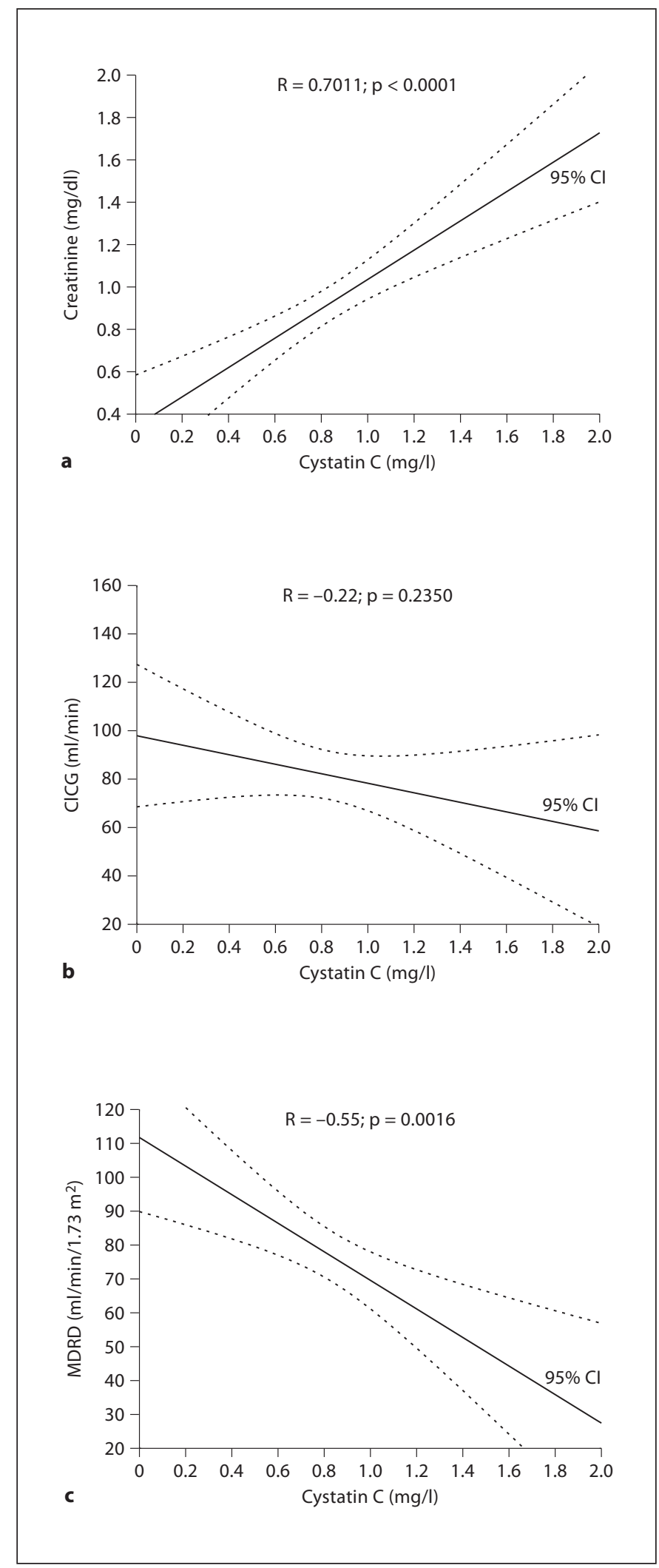

Fig. 3. Correlation between serum cystatin level and creatinine (a), ClCG (b) and MDRD (c) after the sixth cycle of chemotherapy. es in cystatin C serum level, depending on the extent of the residual disease.

Biochemical parameters presented a correlation between cystatin $\mathrm{C}$ and serum marker CA-125 before chemotherapy (Spearman's $\mathrm{R}=0.4 ; \mathrm{p}=0.02$ ), and after the first cycle (Spearman's $\mathrm{R}=0.43 ; \mathrm{p}=0.04$ ). After the second cycle of chemotherapy, we did not observe any correlations between serum level of cystatin $\mathrm{C}$ and serum marker CA-125 (table 3).

\section{Discussion}

Our results indicate that in ovarian cancer patients, cystatin $\mathrm{C}$ serum level is not a better marker of renal function than GFR estimating equations using serum creatinine, or MDRD or ClCG formulas. At the initial stage of treatment, before chemotherapy, we did not see any relationship between serum cystatin $\mathrm{C}$ concentration and the other GRF markers. After the third cycle of chemotherapy, we observed a weak correlation between cystatin C and GFR assessed by the MDRD formula, but the other markers of GFR - serum creatinine and ClCG - did not correlate with cystatin serum level. After first-line chemotherapy, we observed a significant positive relationship between serum cystatin C and creatinine serum concentrations and MDRD.

For the calculation of adequate doses of nephrotoxic agents like cisplatin, a precise estimation of kidney function is obligatory in each patient. However, standard methods for GFR determination have previously been shown to have a lot of disadvantages. Serum-creatininebased methods depend on patient variables. Gold standards like inulin clearance as well as scintigraphic investigations are expensive and expend time. Recent studies suggest that serum cystatin $\mathrm{C}$ may serve as a reliable alternative clinical marker of renal function. Our study did not confirm this observation, indicating the unreliability of cystatin $\mathrm{C}$ as a marker of glomerular function in cancer patients. Similarly, Nakai et al. [18] reported that cystatin $\mathrm{C}$ serum levels are not always a reliable marker of GFR in patients with a malignancy. The authors observed that the correlation coefficient $\mathrm{R}$ between serum cystatin $\mathrm{C}$ level and creatinine clearance was significantly lower in patients with a malignancy than in patients with various degrees of renal function. In other studies, a correlation between serum cystatin $C$ level and the reciprocal of creatinine was seen. Stabuc et al. [19] showed that measurement of serum cystatin $C$ is superior to serum creatinine in the detection of decreased creatinine clearance and, 
Table 3. Correlations between serum cystatin C and CA-125 levels during treatment

\begin{tabular}{|c|c|c|c|c|c|c|}
\hline & Mean & $\min .95 \% \mathrm{CL}$ & $\max .95 \% \mathrm{CL}$ & SD & Spearman's R & $\mathrm{p}$ \\
\hline Cystatin C (before), mg/l & 0.70 & 0.63 & 0.77 & 0.20 & 0.41 & $0.0206^{*}$ \\
\hline CA-125 (before), $\mathrm{U} / \mathrm{ml}$ & 592.62 & 222.91 & 962.33 & $1,092.67$ & & \\
\hline Cystatin C (1st), mg/l & 0.71 & 0.65 & 0.78 & 0.20 & 0.43 & $0.0388^{*}$ \\
\hline CA-125 (1st), U/ml & 121.24 & 54.24 & 188.23 & 162.30 & & \\
\hline Cystatin C (2nd), mg/l & 0.70 & 0.64 & 0.75 & 0.16 & 0.08 & 0.7000 \\
\hline CA-125 (2nd), U/ml & 198.69 & 14.03 & 383.34 & 503.41 & & \\
\hline Cystatin C (3rd), mg/l & 0.70 & 0.63 & 0.75 & 0.18 & -0.11 & 0.5689 \\
\hline CA-125 (3rd), U/ml & 82.70 & 7.96 & 157.44 & 217.57 & & \\
\hline Cystatin C (4th), mg/l & 0.73 & 0.68 & 0.80 & 0.16 & -0.32 & 0.1515 \\
\hline CA-125 (4th), U/ml & 29.44 & 18.80 & 40.08 & 25.78 & & \\
\hline Cystatin C (5th), mg/l & 0.76 & 0.70 & 0.82 & 0.17 & -0.04 & 0.8578 \\
\hline CA-125 (5th), U/ml & 34.14 & 12.92 & 55.35 & 57.83 & & \\
\hline Cystatin C (6th), mg/l & 0.80 & 0.70 & 0.91 & 0.30 & -0.03 & 0.8716 \\
\hline CA-125 (6th), U/ml & 31.16 & 13.72 & 48.61 & 51.55 & & \\
\hline
\end{tabular}

$\mathrm{CL}=$ Confidence limit. ${ }^{*}$ Significant correlation at $\mathrm{p}<0.05$.

potentially, in GFR estimation in cancer patients regardless of the presence of metastases or chemotherapy. In children with cancer treated with various polychemotherapeutic regimens, Bárdi et al. [20] demonstrated that cystatin C may represent a suitable marker for the GFR estimation. Benöhr et al. [21] showed that cystatin C is a reliable marker for monitoring kidney function in patients with normal kidney function receiving cisplatinbased chemotherapy. Cystatin $\mathrm{C}$ turned out to be more sensitive than serum creatinine and its calculated clearances for GFR determination in the so-called creatinineblind range. However, the studies presented above included patients with different types of cancer and treated with different therapeutic regimens. In our study, a homogenous study population (ovarian cancer patients) treated only with one regimen consisting of paclitaxel and cisplatin, a nephrotoxic chemotherapeutic agent, was investigated.

There are several limitations to this analysis. First of all, we used only a small study population; however, the intention of the current work was to assess the correlation between cystatin C and other available GFR markers. We achieved a power of 0.85 by inclusion of the required sample size of at least 32 patients. Secondly, we did not compare the cystatin C serum level with the gold standard for GFR assessment - clearance of inulin, an ideal filtration marker - or alternative exogenous markers such as iothalamate, diethylene triamine pentaacetic acid (CrEDTA) and iohexol.

In our study, we found significant differences in cystatin $\mathrm{C}$ serum levels before and after the first and second cycles of chemotherapy, depending on the presence of measurable residual disease shown by spiral CT. After the third or later cycles of chemotherapy, we did not observe any significant differences in cystatin $C$ serum level related to the extent of residual disease. Further, we found a correlation between cystatin C and the CA-125 serum marker before chemotherapy and after the first cycle of chemotherapy. After the second or later cycles of chemotherapy, we did not observe any correlations between cystatin C serum level and CA-125 serum marker.

The results of our study suggest that the serum levels of cystatin $\mathrm{C}$ in ovarian cancer patients are probably in a relation to its nature as a cysteine protease inhibitor. Our results are consistent with previous studies revealing increased levels of serum cystatin C in colorectal, head and neck cancer patients $[22,23]$. Similarly, Tumminello et al. [24] reported that cystatin C is significantly increased in patients with breast cancer or prostate cancer with bone metastasis in comparison to healthy subjects or to patients with nonmalignant diseases. The increased lev- 
els of cystatin C in cancer patients do not seem to result from impaired kidney function as none of these patients showed clinically evident alteration in renal function. In another study, Mulaomerović et al. [25] showed that the cystatin $\mathrm{C}$ serum level was significantly increased either in patients with non-Hodgkin B cell lymphoma without therapy or in those with therapy compared to healthy controls. Therefore, these data are consistent with those from other studies reporting that cystatin $\mathrm{C}$ levels are enhanced in malignant tissues or in body fluids of patients with neoplastic diseases, and that this phenomenon is associated with more aggressive forms of these tumors [26].

The relevance of cystatin $\mathrm{C}$ to human reproductive disorders has been analyzed by Nakanishi and colleagues [27]. The authors evaluated cystatin in tissues and serum of patients with benign and malignant ovarian lesions and found that the serum concentration of cystatin $\mathrm{C}$ was significantly higher in the patients than in the control group. These findings suggest that the regulation of the cathepsin/cystatin system may play an important role in recurrent miscarriage.

Sokol et al. [28] showed that cystatin C not only inhibits cathepsin-mediated invasion, but also antagonizes tumor growth factor (TGF) $-\beta$ signaling in normal and cancer cells by interacting physically with the TGF- $\beta$ type II receptor, thereby preventing TGF- $\beta$ binding; it is a powerful tumor suppressor that normally represses these processes by prohibiting epithelial cell proliferation, and by creating a cell microenvironment that inhibits epithelial cell motility, invasion and metastasis.

In summary, the present study demonstrates that cystatin $\mathrm{C}$ is not a reliable marker for monitoring kidney function in patients with normal kidney function receiving cisplatin-based chemotherapy. In addition, in patients with ovarian cancer, this phenomenon is probably due to its nature as a cysteine protease inhibitor.

\section{References}

1 Mohanram A, Toto R: Measurement of kidney function; in Pereira BJG, Sayegh $\mathrm{MH}$, Blake PG (eds): Chronic Kidney Disease, Dialysis, and Transplantation. A Companion to Brenner and Rector's The Kidney. Philadelphia, Saunders, 2005, pp 20-30.

$\checkmark 2$ Levey AS: Measurement of renal function in chronic renal disease. Kidney Int 1990;38: 167-184.

3 Levey AS, Bosch JP, Lewis JB, Greene T, Rogers N, Roth D: A more accurate method to estimate glomerular filtration rate from serum creatinine: a new prediction equation. Ann Intern Med 1990;130:461-470.

4 Stevens LA, Coresh J, Greene T, Levey AS: Assessing kidney function: measured and estimated glomerular filtration rate. $\mathrm{N}$ Engl J Med 2006;354:2473-2483.

$\checkmark 5$ Risch L, Herklotz R, Blumberg A, Huber AR: Effects of glucocorticoid immunosuppression on serum cystatin C concentrations in renal transplant patients. Clin Chem 2001; 47:2055-2059.

-6 Manetti L, Pardini E, Genovesi M, Campomori A, Grasso L, Morselli LL, Lupi I, Pellegrini G, Bartalena L, Bogazzi F, Martino E: Thyroid function differently affects serum cystatin $\mathrm{C}$ and creatinine concentrations. J Endocrinol Invest 2005;28:346-349.

$\checkmark 7$ Grubb A, Simonsen O, Sturtfelt G, Truedson L, Thysell H: Serum concentration of cystatin $C$, factor $D$ and $\beta_{2}$-microglobulin as a measure of glomerular filtration rate. Acta Med Scand 1985;218:499-503.
8 Stevens LA, Coresh J, Schmid CH, Feldman HI, Froissart M, Kusek J, Rossert J, van Lente F, Bruce RD 3rd, Zhang YL, Greene T, Levey AS: Estimating GFR using serum cystatin C alone and in combination with serum creatinine: a pooled analysis of 3,418 individuals with CKD. Am J Kidney Dis 2008;51: 395-406.

-9 Sloane BF: Suicidal tumor proteases. Nat Biotech 1996;14:826-827.

10 Lah T, Kos J: Cysteine proteinases in cancer progression and their clinical relevance for prognosis. Biol Chem 1998;379:125-130.

11 Hansen T, Petrow PK, Gaumann A, Keyszer GM, Otto M, Kirkpatrick CJ, Kriegsmann J: Expression of cysteine proteinases cathepsins $\mathrm{B}$ and $\mathrm{K}$, and cysteine proteinase inhibitor cystatin $\mathrm{C}$ in giant cell tumor of tendon sheath. Mod Pathol 2001;14:318-324.

12 Yano M, Hirai K, Naito Z, Yokoyama M, Ishiwata T, Shiraki Y, Inokuchi M, Asano G: Expression of cathepsin B and cystatin C in human breast cancer. Surg Today 2001;31: 385-389.

13 Kos J, Werle T, Lah T, Brunner N: Cysteine proteinases and their inhibitors in extracellular fluids: marker for diagnosis and prognosis in cancer. Int J Biol Markers 2000;15 84-89.
- 14 Bodnar L, Wcisło G, Gasowska-Bodnar A, Synowiec A, Szarlej-Wcisło K, Szczylik C: Renal protection with magnesium subcarbonate and magnesium sulphate in patients with epithelial ovarian cancer after cisplatin and paclitaxel chemotherapy: a randomised phase II study. Eur J Cancer 2008;44:26082614.

15 Junge W, Wilke B, Halabi A, Klein G: Determination of reference intervals for serum creatinine, creatinine excretion and creatinine clearance with an enzymatic and a modified Jaffé method. Clin Chim Acta 2004;344:137-148

16 Cockcroft DW, Gault MH: Prediction of creatinine clearance from serum creatinine. Nephron 1976;16:31-41

17 Ray JG, Vermeulen MJ: Sample size estimation for the sorcerer's apprentice: guide for the uninitiated and intimidated. Can Fam Physician 1999;45:1732-1739.

18 Nakai K, Kikuchi M, Fujimoto K, Kaneko Y, Omori S, Nakai K, Suwabe A: Serum levels of cystatin $\mathrm{C}$ in patients with malignancy. Clin Exp Nephrol 2008;12:132-139.

19 Stabuc B, Vrhovec L, Stabuc-Silih M, Ciszej TE: Improved prediction of decreased creatinine clearance by serum cystatin C: use in cancer patients before and during chemotherapy. Clin Chem 2000;46:193-197.

-20 Bárdi E, Bobok I, Oláh AV, Oláh E, Kappelmayer J, Kiss C: Cystatin C is a suitable marker of glomerular function in children with cancer. Pediatr Nephrol 2004;19:1145-1147. 
-21 Benöhr P, Grenz A, Hartmann JT, Müller GA, Blaschke S: Cystatin C: a marker for assessment of the glomerular filtration rate in patients with cisplatin chemotherapy. Kidney Blood Press Res 2006;29:32-35.

-22 Kos J, Krasovec M, Cimerman N, Nielsen HJ, Christensen IJ, Brünner N: Cysteine proteinase inhibitors stefin $A$, stefin $B$, and cystatin $\mathrm{C}$ in sera from patients with colorectal cancer: relation to prognosis. Clin Cancer Res 2000;6:505-511.

-23 Strojan P, Svetic B, Smid L, Kos J: Serum cystatin $\mathrm{C}$ in patients with head and neck carcinoma. Clin Chim Acta 2004;344:155-161.
24 Tumminello FM, Flandina C, Crescimanno M, Leto G: Circulating cathepsin K and cystatin $\mathrm{C}$ in patients with cancer-related bone disease: clinical and therapeutic implications. Biomed Pharmacother 2008;62:130 135.

25 Mulaomerović A, Halilbasić A, Cickusić E, Zavasnik-Bergant T, Begić L, Kos J: Cystatin $\mathrm{C}$ as a potential marker for relapse in patients with non-Hodgkin B-cell lymphoma. Cancer Lett 2007;248:192-197.

26 Keppler D: Towards novel anticancer strategies based on cystatin function. Cancer Lett 2006;235:159-176.
27 Nishikawa H, Ozaki Y, Nakanishi T, Blomgren K, Tada T, Arakawa A, Suzumori $\mathrm{K}$ : The role of cathepsin $\mathrm{B}$ and cystatin $\mathrm{C}$ in the mechanisms of invasion by ovarian cancer. Gynecol Oncol 2004;92:881-886.

28 Sokol JP, Neil JR, Schiemann BJ, Schiemann WP: The use of cystatin $C$ to inhibit epithelial-mesenchymal transition and morphological transformation stimulated by transforming growth factor- $\beta$. Breast Cancer Res 2005;7:R844-R853. 